\title{
Analysis of a New Dissipation System for a Solar Cooling Installation
}

\author{
Carlos Monné Bailo, ${ }^{1}$ Sergio Alonso Garcés, ${ }^{1}$ and Fernando Palacín Arizón ${ }^{2}$ \\ ${ }^{1}$ Group of Thermal Engineering and Energy Systems (GITSE), Department of Mechanical Engineering, \\ Aragon Institute of Engineering Research (I3A), University of Zaragoza, C/María de luna s/n, 50018 Zaragoza, Spain \\ ${ }^{2}$ Bioclimatic Architecture Department, National Renewable Energy Centre (CENER), Ciudad de la Innovación, No. 7; \\ 31621 Sarriguren (Navarra), Spain
}

Correspondence should be addressed to Carlos Monné Bailo, cmmb@unizar.es

Received 28 September 2010; Accepted 21 November 2010

Academic Editor: Nesreene Ghaddar

Copyright (C) 2010 Carlos Monné Bailo et al. This is an open access article distributed under the Creative Commons Attribution License, which permits unrestricted use, distribution, and reproduction in any medium, provided the original work is properly cited.

\begin{abstract}
This paper describes a solar absorption cooling installation located at the University of Zaragoza (Spain). The installation is based on the performance of an absorption chiller. The solar cooling system consists of $37,5 \mathrm{~m}^{2}$ of flat plate collector, a $4.5 \mathrm{~kW}$, singleeffect $\mathrm{LiBr}-\mathrm{H}_{2} \mathrm{O}$ absorption chiller, and a dry cooling tower. The installation provides cooling to a gymnasium belonging to the sports center of the university. To carry out the installation analysis, the system was continuously monitored. In 2007, 2008 and 2009 , several studies have been performed in order to analyze the full system operation. The measured data showed the strong influence of the cooling water temperature and the generator driving temperature on the COP. Due to the experimental evidence of the influence of the cooling water temperature, a new heat rejection system based on a geothermal heat sink has been installed and studied.
\end{abstract}

\section{Introduction}

Nowadays, most of the refrigeration demand is covered by electrical compression systems [1]. Due to the operation of this air conditioning machines, the electricity demand reaches high values, causing technical problems and increasing electricity prices. As a consequence, alternative refrigeration equipments which profit from renewable or residual energies have been developed. One of these alternatives is a solar system coupled with an absorption chiller, which uses solar thermal energy to refrigerate.

The use of solar energy in refrigeration is especially interesting because the period with more solar radiation, and therefore the period with the highest solar thermal energy production, is the period in which the refrigeration demand is higher [2]. This technology based on thermodynamics cycles is contrasted in the industrial sector, but it does not have enough real experiences in the domestic sector (low power). Therefore, research and development activities are necessary in order to reduce the cost of using solar-assisted air conditioning [3]. There are a lot of researches referred to theoretical studies [4-7], but the information about experimental studies in this kind of installations is scarce [8]. New absorbents $[9,10]$ and temperature-entropy diagrams [11] have been analyzed and numerous simulations have been carried out with TRNSYS [12-14]. While the theoretical and simulation studies work with only arbitrary parameters (fixed by the researcher), an experimental study works with the real variation of these parameters. This represents an advantage of this type of studies because in that way we can see the real performance of the system analyzed.

Since 2007, the solar cooling installation of the sports centre (SAD) of the University of Zaragoza has been studied (Figure 1). This installation, with a $37.5 \mathrm{~m}^{2}$ solar field of flat collectors, supplies heating power to the rotary absorption machine (Rotartica Solar 045). This chiller supplies the chilling water to the fancoils of a gymnasium [15]. The solar cooling system was installed as a solution to the overheating problems in the solar collectors, which supplied the domestic hot water demand of the building. During the first two years, 


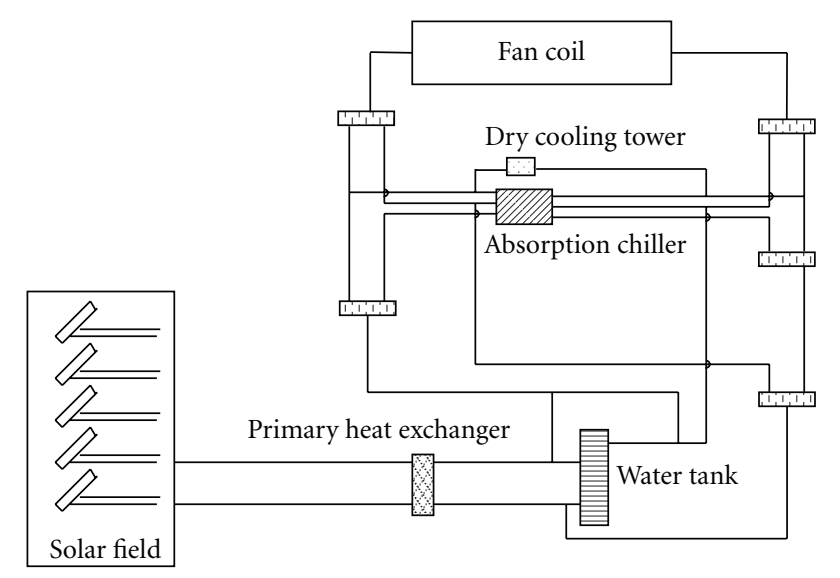

FIGURE 1: Scheme of the main installation.

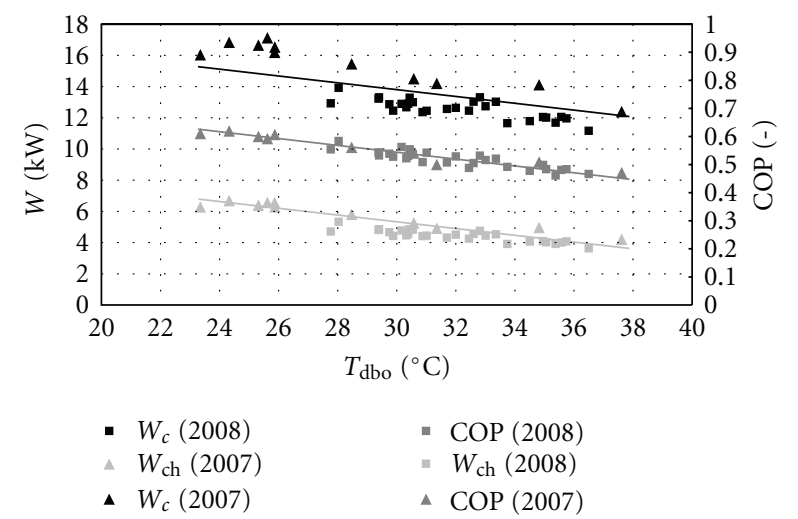

FIGURE 2: Influence of the outdoor temperature in chilling power, cooling power, and COP.

the installation operated with a dry cooling tower as heat rejection system [16].

With the objective of increasing the energetic performance of the absorption machine, and therefore the overall installation performance, several studies were carried out using dynamic simulation software and analytical methods [17]. The analysis of the installation equipped with the initial heat rejection system showed the strong influence of the heat rejection temperature (outdoor temperature) on the COP (Figure 2); when the outdoor temperature increases, the cooling power and the COP decrease.

\section{New Heat Rejection System}

Two options were proposed in order to improve the heat rejection system: a wet cooling tower and a geothermal system. With both of them, the installation performance should improve. The wet cooling tower was ruled out due to its problem of legionella risks. Apart from this disadvantage, the performance of the wet cooling tower would have been limited by the outdoor temperature and the humidity conditions. Furthermore, the water consumption should have been taken into account.

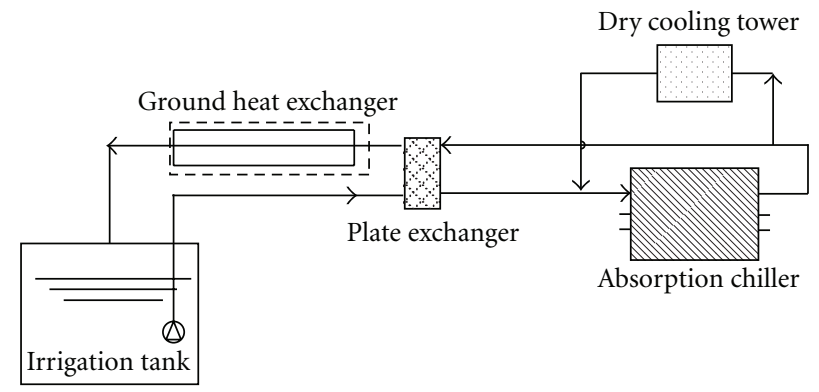

FIgURE 3: Scheme of the design of the new system of dissipation.

The second option was using a geothermal system as a heat rejection system. At this point, two options were considered: open cycles and closed cycles.

Technical and economic feasibility studies were performed in order to compare three different geothermal systems [18]: closed geothermal circuit with vertical heat exchangers, closed geothermal circuit with horizontal heat exchangers, and open geothermal circuit using a water tank close to the building. Finally, the heat rejection system chosen was the open circuit one.

The new circuit uses a water tank of about $25 \mathrm{~m}^{3}$. It is located in the surroundings of the solar cooling installation, and it is used as an irrigation tank. The tank is filled from an underground well. The water tank is filled daily in summer, because it is used to irrigate the sports ground of the SAD. Therefore, the water temperature of the tank will keep constant, solving the possible problems of thermal saturation of the contained water. The new geothermal installation is shown in Figure 3.

The new heat rejection system extracts the heat produced by the absorption cycle by means of a $20 \mathrm{~kW}$ plate heat exchanger. There is a by-pass that leads the water directly to the plate heat exchanger avoiding the dry cooling tower. The overall length of the new circuit is $190.5 \mathrm{~m}$, of which $90.5 \mathrm{~m}$ have been divided into three pipes with a smaller diameter. The aim is to increase the heat exchange surface between the pipes and the ground (Figure 4). Hence, the dissipation of the heat generated by the absorption machine will take place in two sinks: the water tank and the geothermal horizontal exchanger.

The installation costs of the new heat rejection system were $18000 €$ while the price of the absorption chiller (including the dry cooling tower) was $14000 €$. The operation cost is similar in both systems. Then, if we want to choose one heat rejection system, we should know the electricity price too.

Since the initial dry cooling tower was not removed from the installation, the rotary chiller can operate with a hybrid heat rejection system. The produced heat of the absorption chiller can be evacuated to the initial dry cooler tower or to the geothermal system.

\section{Methodology}

The installation has a PLC unit (PXC52) and a web controller (PXM20) that form the control and data acquisition system, 


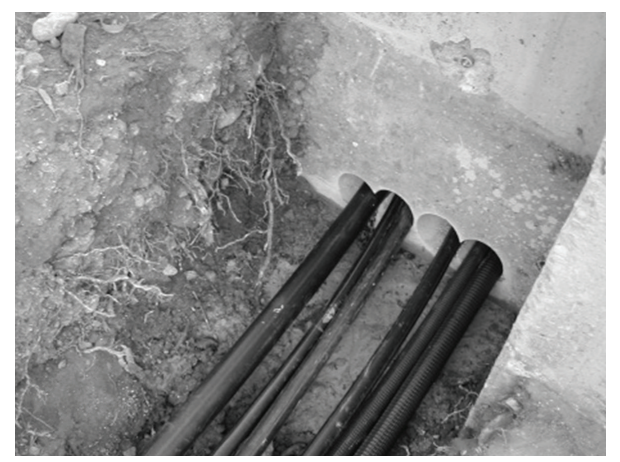

(a)

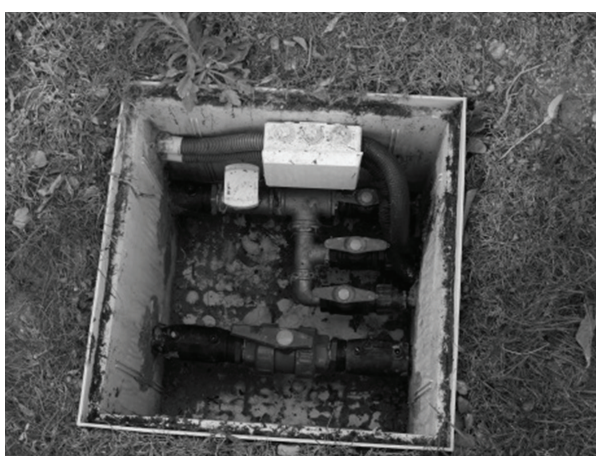

(b)

FIGURE 4: Detail of the three pipes that form the geothermal exchanger, the geothermal supply pipe, and the electrical connections.

along with temperature probes, humidity probes, radiation probes, energy counters, and flowmeters (Table 1).

The monitoring system was designed to carry out different energy and mass balances at the different elements of the installation. The first step of the monitoring methodology is the primary variables data collection (water circuit temperatures, solar radiation, outdoor temperature and humidity, etc.). Once these variables have been verified and analyzed (primary variables), secondary variables are calculated. These secondary variables are thermal power, efficiency of the solar collectors, COP. The most important secondary variables are

(i) thermal power transferred to the generator:

$$
W_{g}=q_{g} \cdot C_{p} \cdot\left(T_{i, g}-T_{o, g}\right)
$$

(ii) thermal power dissipated at the heat rejection system:

$$
W_{c}=q_{c} \cdot C_{p} \cdot\left(T_{i, c}-T_{o, c}\right)
$$

(iii) thermal power absorbed at the evaporator (chilling effect):

$$
W_{\mathrm{ch}}=q_{\mathrm{ch}} \cdot C p \cdot\left(T_{i, \mathrm{ch}}-T_{o, \mathrm{ch}}\right),
$$

(iv) coeficcient of performance of the chiller:

$$
\mathrm{COP}=\frac{W_{\mathrm{ch}}}{\left(W_{e}+W_{g}\right)} .
$$

When these variables are calculated, four different types of graphics are plotted (rank graphics, phase graphics, steady state graphics, and trend graphics) in order to evaluate the performance of the installation. The most important graphics are the trend graphics, because they show the influence of one variable on the others. In this kind of graphics, the mean values reached at the steady state of the studied variables are shown. To elaborate these trend graphics, it is necessary to define a steady state, which is the period of time inside $\left[\left(T_{o, \mathrm{ch}}\right)_{\min }, 1.05 \cdot\left(T_{o, \mathrm{ch}}\right)_{\min }\right] . T_{o \text {,ch }}$ has been chosen to define the stationary time due to its constant development. In this interval of time, the performance of the installation and the absorption machine in the different days analyzed can be compared.

After the analysis of the installation with the dry cooling tower in 2007 and 2008, the great influence of the heat sink temperature on the COP of the chiller was clear (Figure 2). Mean values of some important variables of the installation in these years are shown in Table 2.

The geothermal installation was installed in the first half of 2009. In that year, in the first month of operation, the system used the dry cooling tower. In the second month already, the chiller started to operate with the geothermal sink as a heat rejection system. To evaluate the performance of the chiller with the new heat rejection system, two different flows were tested for the geothermal circuit (491/min y $95 \mathrm{l} / \mathrm{min}$ ). This experience would allow analyzing the effect of the flow on the installation.

\section{Results}

The obtained results during the first month of operation in 2009 were similar to the ones obtained in previous years. In Figure 5, some variables of the installation working with the dry cooling tower are shown. As it can be seen, if the outdoor temperature rises, the chilling power decreases. This is caused because if the dry bulb temperature of the sink (ambient temperature) increases, the heat rejection capacity of the dry cooler reject diminishes. If this capacity decreases, all the flows inside the chiller increase their temperatures, including the chilling flow. Consequently, the performance of the chiller gets worse. These results are similar to others [19, 20], where the relation between COP, power, and outdoor temperature and the slope of the trend lines is the same.

The obtained results, compared with the initial ones, are shown in Figures 6 and 7. In Figure 6, the evolution of chilling and cooling capacity is plotted against the outdoor temperature. When the installation evacuates heat by means of the new geothermal system, the influence of the outdoor temperature almost disappears. In this way the behaviour of the chiller temperatures shows a constant tendency. This occurs because the sink temperature (water well) does not fluctuate with the outdoor temperature. If the temperature of the sink was lower, their tendencies would show a horizontal behaviour as well and their values would be lower in the graphics. This fact will produce lower temperatures at the return of the machine, increasing the rejection capacity and, therefore, its chilling power [21]. If we compare the trend 
TABLE 1: Main measurement elements used at the installation.

\begin{tabular}{lccc}
\hline Measurement element & Reference & Frecuency of measurement & Error \\
\hline Outdoor temperature & Siemens QFA 3160 & 5 minutes & $\pm 0.8^{\circ} \mathrm{C}$ \\
Radiation probe & Quimisur IQ-5.0 & 5 minutes & $\pm 2 \%$ \\
Energy counter & Siemens 2WR5 & 20 seconds & $\pm 2-4 \%$ \\
Temperature probe (water) & Siemens QAE 21, Siemens QAD 22 & 20 seconds & $\pm 0.8^{\circ} \mathrm{C}$ \\
\hline
\end{tabular}

TABLE 2: Mean values of chilling power and COP in 2007 and 2008.

\begin{tabular}{lcc}
\hline Year & $W_{\text {ch }}(\mathrm{kW})$ & COP $(-)$ \\
\hline 2007 & 5.7 & 0.57 \\
2008 & 4.4 & 0.51 \\
\hline
\end{tabular}

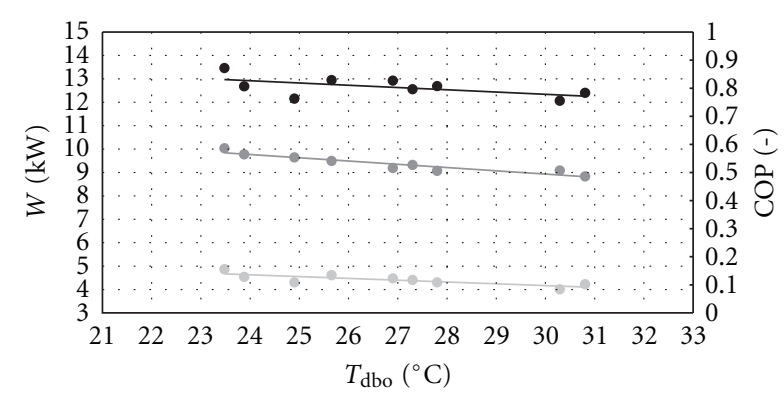

- $W_{c}(2009)$

- $W_{\mathrm{ch}}(2009)$

- COP (2009)

FIGURE 5: Evolution of power and COP versus outdoor temperature using the dry cooling tower.

lines of the chilling power of the new heat rejection system with the dry cooler system, we can see that the performance has changed $[22,23]$. It is interesting to analyze the point in which both lines are crossed. As it can be noted, below the outdoor temperature of $34^{\circ} \mathrm{C}$, the best system to use as heat rejection system is the dry cooling tower because the value of chilling power is higher but from this point, if the outdoor temperature keeps growing, the chilling power obtained with the geothermal heat rejection system is higher (when the geothermal system flow is $951 / \mathrm{min}$ ). As a result, a hybrid control system can be implemented in the installation. This control will choose at every moment the best heat sink to use in order to optimize the performance of the heat rejection system of the chiller (up to outdoor temperature values of $34^{\circ} \mathrm{C}$, the dry cooling tower will be used and from this value, the geothermal system will be the chosen one).

Figure 7 indicates that the COP result tendency is similar to the cooling power tendency. When the geothermal flow is lower $(49 \mathrm{l} / \mathrm{min})$, the COP is smaller than the one obtained with the usage of the dry cooling tower (up to when the outdoor temperature reaches $38^{\circ} \mathrm{C}$ ). However, for the highest flow rate, the COP is better in the new scenario if the outside temperature is over $33^{\circ} \mathrm{C}$. This also means that a hybrid control system should be taken in account in order to always use the most thermally efficient sink as heat rejection system.

The results of the initial studies performed in order to install the new heat rejection system showed important

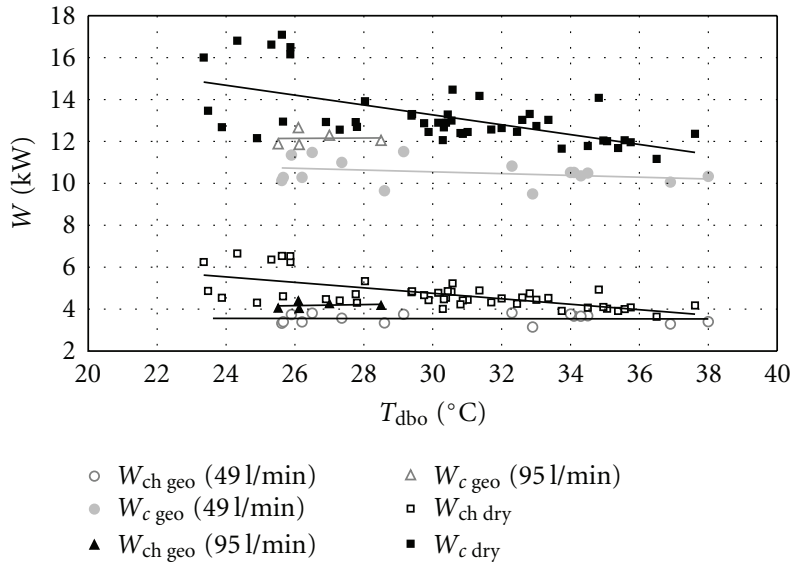

Figure 6: Chilling capacity and rejected heat power with the dry cooler and the new geothermal sink.

improvements on the chilling power and the chiller COP. The new heat rejection conditions were more favourable for the chiller that the old ones. The new temperature of the heat sink was, according to the owner of the water wells placed close to ours, $17^{\circ} \mathrm{C}$, and the volume of the water tank was $25 \mathrm{~m}^{3}$. With these new design conditions, the chilling capacity of the chiller will achieve $7.5 \mathrm{~kW}$ with a COP of 0.74 . Unfortunately, during the operation period in 2009, water well temperature was about $25^{\circ} \mathrm{C}$, a value that is far from the historical data of the rest of the wells in that zone. With that temperature, the new estimated values were $6.7 \mathrm{~kW}$ of chilling capacity and a COP of 0.62 . As it is shown in Table 3, this estimation has not been accomplished. Although only partially satisfactory results have been obtained with the new rejection system, it has been shown that the mean value of the COP measured in 2009 is slightly better than the one measured in 2008 as shown in Table 3. The average COP values for $49 \mathrm{l} / \mathrm{min}$ and for $95 \mathrm{l} / \mathrm{min}$ were 0.47 and 0.52 , respectively. Even so, the COP obtained with the highest flow value was slightly better than the value obtained in 2008 . Therefore the implementation of a hybrid heat rejection control can be assumed in order to improve the performance of the installation. Besides, during 2010, the plate heat exchanger of the geothermal circuit is going to be redesigned according to the real operational conditions.

\section{Conclusions}

In this paper, the results of the analysis of the performance of a solar-powered absorption system have been presented. Initially, a dry cooling tower was installed to reject the 


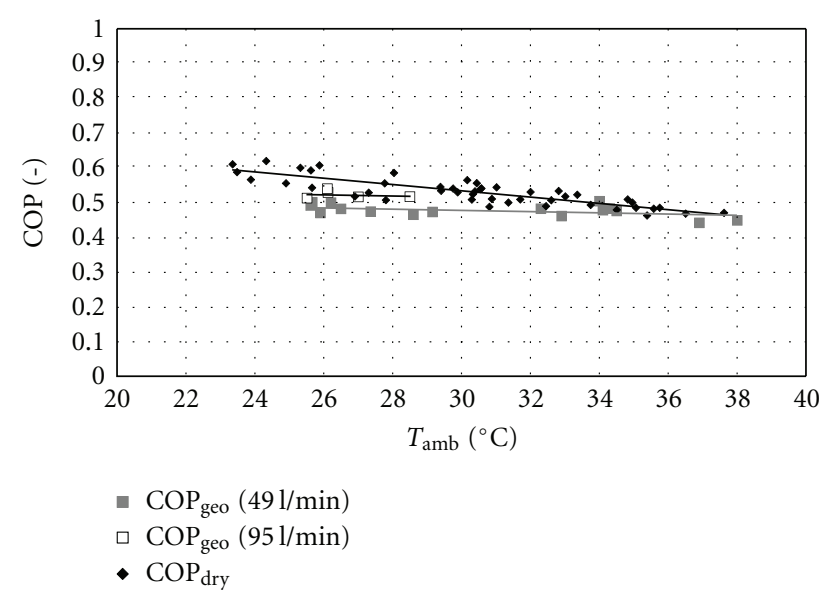

FIGURE 7: COP results with the dry cooler and the new geothermal sink.

TABLE 3: Experimental mean values of the installation with the geothermal system in the year 2009.

\begin{tabular}{lcccc}
\hline Flow rate $(\mathrm{l} / \mathrm{min})$ & $W_{\text {ch }}(\mathrm{kW})$ & $W_{g}(\mathrm{~kW})$ & $W_{c}(\mathrm{~kW})$ & COP $(-)$ \\
\hline 49 & 3.50 & 7.1 & 10.5 & 0.47 \\
95 & 4.2 & 7.6 & 12.2 & 0.52 \\
\hline
\end{tabular}

absorption cycle heat. The first results showed a great influence of the ambient temperature on the COP of the chiller. Because of this, an open geothermal cycle was designed and installed, allowing the use of a hybrid heat rejection system since the dry cooler was not removed from the installation. With the new heat rejection system, the influence of the ambient temperature on the performance of the chiller was resolved, and therefore a constant COP was obtained.

These studies have proved the importance of the design of the flat heat exchanger placed between the cooling loop of the chiller and the geothermal circuit. Due to differences between the estimated operation conditions and the real operation conditions of the new water sink temperature, the measured performance results are not as good as the expected ones. In any case, the mean value of the COP of the chiller has been improved compared with the mean value of the year 2008. Several studies have been already planned for the next year to optimize the geothermal installation, in order to reach the expected results.

Lastly, depending on the planned optimization of the plate heat exchanger, a condensation hybrid system control could be designed. The possibility of using a hybrid system (air/water cooled) to reject the produced heat in the absorption cycle is another option to take into account to improve the performance of the chiller.

\section{Nomenclature}

COP: coefficient of performance (-)

q: $\quad$ flow rate $\left(\mathrm{min}^{-1}\right)$
$T: \quad$ temperature $\left({ }^{\circ} \mathrm{C}\right)$

$W$ : power $(\mathrm{kW})$

$C_{p}:$ specific heat of water

$W_{e}$ : electricity consumption of the chiller.

\section{Subscripts}

c: cooling

ch: chilling

dbo: dry bulb outdoor

dry: dry cooling system

$i$ inlet

$o$ : outlet

$g:$ generator

geo: geothermal system.

\section{References}

[1] SolarCombi+, "Identification of Most Promising Markets and Promotion of Standardized System Configurations for the Market Entry of Small Scale Combined Solar Heating \& Cooling Applications (Solar Combi+)," SolarCombi+, 2008, http://www.solarcombiplus.eu/.

[2] K. Herold, R. Radermacher, and S. A. Klein, Absorption Chillers and Heat Pumps, CRS Press LLC, 1996.

[3] C. A. Balaras, G. Grossman, H. M. Henning et al., "Solar air conditioning in Europe-an overview," Renewable and Sustainable Energy Reviews, vol. 11, no. 2, pp. 299-314, 2007.

[4] X. G. Casals, "Solar absorption cooling in Spain: perspectives and outcomes from the simulation of recent installations," Renewable Energy, vol. 31, no. 9, pp. 1371-1389, 2006.

[5] F. Assilzadeh, S. A. Kalogirou, Y. Ali, and K. Sopian, "Simulation and optimization of a $\mathrm{LiBr}$ solar absorption cooling system with evacuated tube collectors," Renewable Energy, vol. 30, no. 8, pp. 1141-1159, 2005.

[6] H. M. Henning, "Solar assisted air conditioning of buildingsan overview," Applied Thermal Engineering, vol. 27, no. 10, pp. 1734-1749, 2007.

[7] O. Kaynakli and M. Kilic, "Theoretical study on the effect of operating conditions on performance of absorption refrigeration system," Energy Conversion and Management, vol. 48, no. 2, pp. 599-607, 2007.

[8] A. Syed, M. Izquierdo, P. Rodríguez et al., "A novel experimental investigation of a solar cooling system in Madrid," International Journal of Refrigeration, vol. 28, no. 6, pp. 859$871,2005$.

[9] A. de Lucas, M. Donate, C. Molero, J. Villaseñor, and J. F. Rodríguez, "Performance evalution and simulation of a new absorbent for an absorption refrigeration system," International Journal of Refrigeration, vol. 27, no. 4, pp. 324330, 2004.

[10] J. I. Yoon and O. K. Kwon, "Cycle analysis of air-cooled absorption chiller using a new working solution," Energy, vol. 24, no. 9, pp. 795-809, 1999.

[11] R. Tozer, A. Syed, and G. Maidment, "Extended temperatureentropy (T-s) diagrams for aqueous lithium bromide absorption refrigeration cycles," International Journal of Refrigeration, vol. 28, no. 5, pp. 689-697, 2005.

[12] A. A. Argiriou, C. A. Balaras, S. Kontoyiannidis, and E. Michel, "Numerical simulation and performance assessment of a low capacity solar assisted absorption heat pump coupled with a 
sub-floor system," Solar Energy, vol. 79, no. 3, pp. 290-301, 2005.

[13] M. Balghouthi, M. H. Chahbani, and A. Guizani, "Solar powered air conditioning as a solution to reduce environmental pollution in Tunisia," Desalination, vol. 185, no. 1-3, pp. 105$110,2005$.

[14] I. Atmaca and A. Yigit, "Simulation of solar-powered absorption cooling system," Renewable Energy, vol. 28, no. 8, pp. 1277-1293, 2003.

[15] C. Monné Bailo, J. Guallar, S. Alonso, and F. Palacín, "Instalación experimental de refrigeración solar," Era Solar, vol. 149, pp. 18-30, 2009.

[16] F. Palacín, "Refrigeración Solar," in Jornadas Técnicas FOROCLIMA '09, Madrid, Spain, Febrero 2009.

[17] C. Monne, F. Palacin, L. Serra, and S. Alonso, "Monitoring and dynamic simulation of an existing solar powered absorption cooling system in Zaragoza," in Proceedings of the 5th Dubrovnik Conference on Sustainable Development of Energy Water and Environment Systems, Dubrovnik, Croatia, 2009.

[18] J. Heredero, Sistema de intercambio geotérmico para un equipo de Refrigeración Solar por absorción, Proyecto fin de carrera. Universidad de Zaragoza, Zaragoza, Spain, 2009.

[19] F. Besana, J. Rodriguez, G. Nurzia, and W. Sparber, "Heat rejection for solar combi+ systems: dry cooler and wet cooling tower," in Proceedings of the 1st International Conference On Solar Heating, Cooling (EUROSUN '08), Lisboa, Portugal, 2008.

[20] M. Izquierdo, R. Lizarte, J. D. Marcos, and G. Gutiérrez, "Air conditioning using an air-cooled single effect lithium bromide absorption chiller: results of a trial conducted in Madrid in August 2005," Applied Thermal Engineering, vol. 28, no. 8-9, pp. 1074-1081, 2008.

[21] C. Monné, F. Palacín, and S. Alonso, "Comparing different sinks of heat rejection of an existing solar powered absorption cooling system," in Proceedings of International Conference on Renewable Energy and Power Quality (ICREPQ '10), Granada, Spain, 2010.

[22] C. Monné, F. Palacín, S. Alonso, J. M. Izquierdo, and J. Heredero, "Análisis experimental del comportamiento dinámico de una instalación de Refrigeración Solar por absorción," Era Solar, vol. 156, pp. 6-16, 2009.

[23] C. Monné, S. Alonso, F. Palacín, and L. Serra, "Monitoring and simulation of an existing solar powered absorption cooling system in Zaragoza (Spain)," Applied Thermal Engineering, vol. 31, no. 1, pp. 28-35, 2011. 

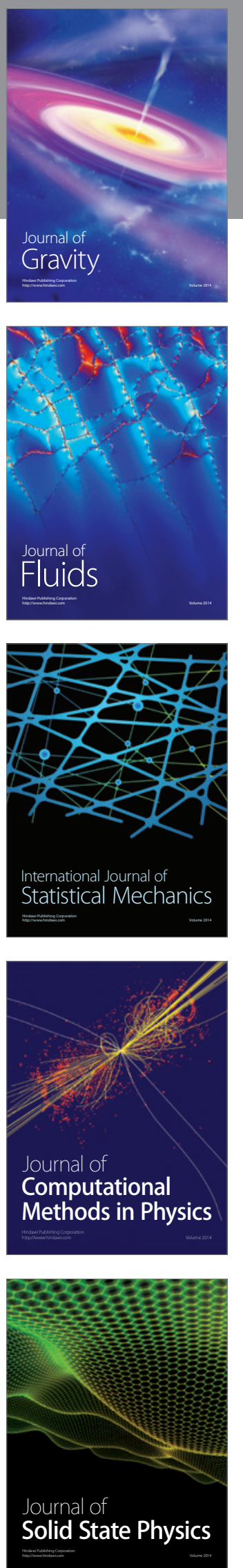

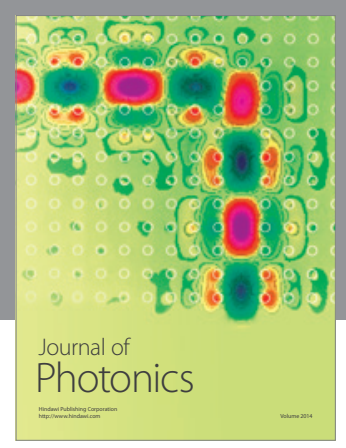

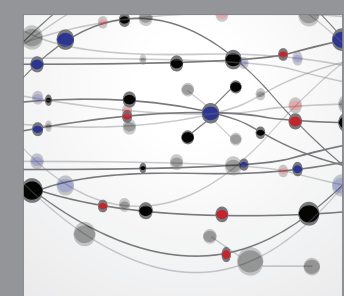

The Scientific World Journal
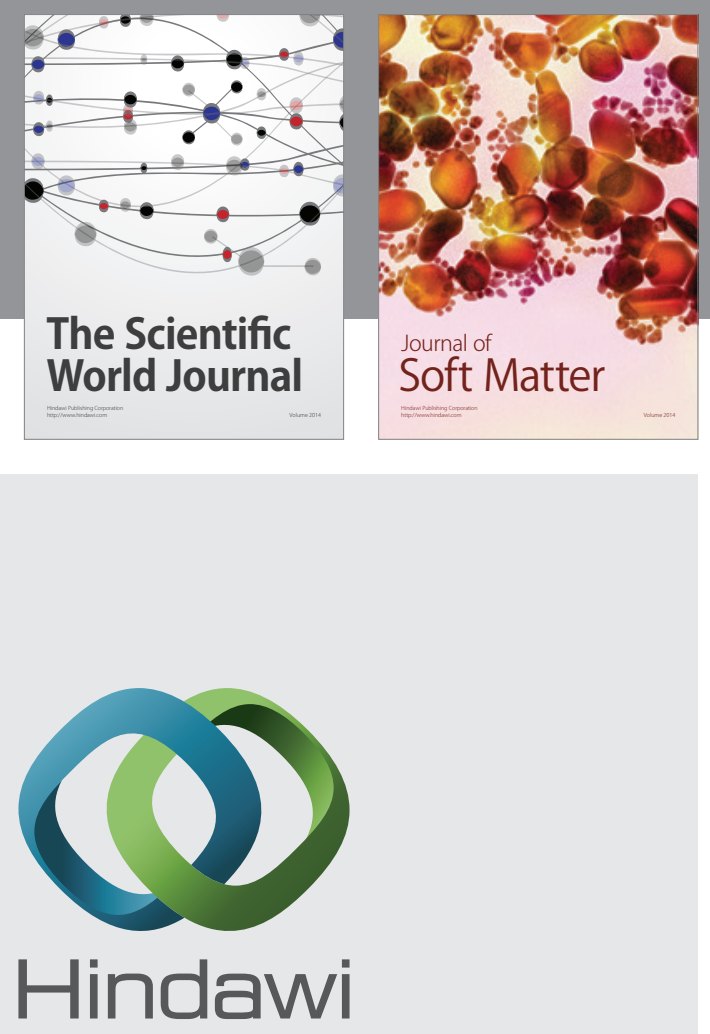

Submit your manuscripts at

http://www.hindawi.com
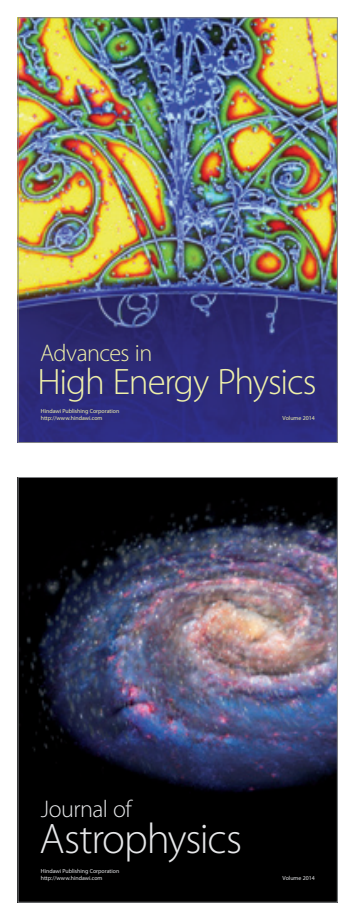
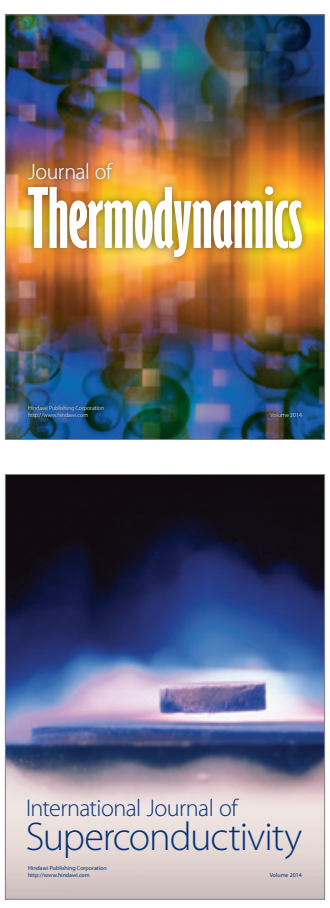
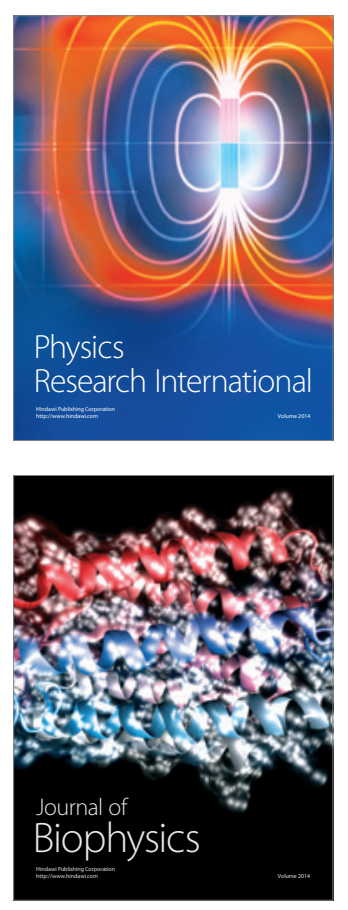
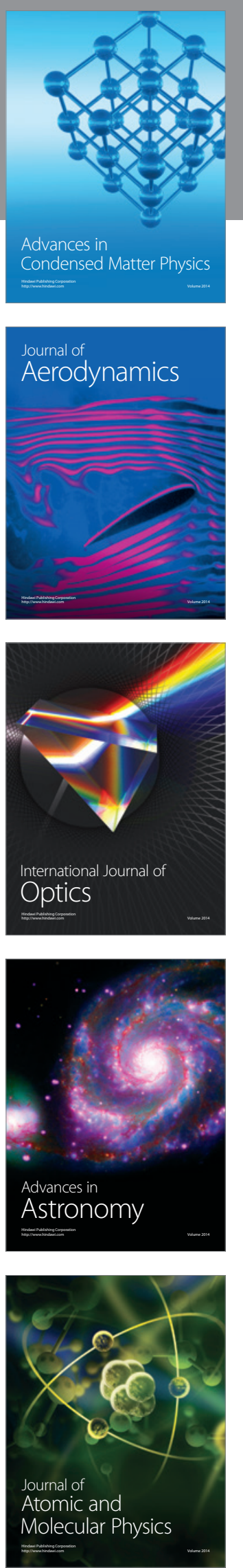